\title{
O FUTEBOL: QUESTÕES E REFLEXÕES A RESPEITO DESSA “PROFISSÃO”
}

\author{
Larissa Cerignoni Benites* \\ FABIo Augusto BARBIERI ${ }^{* *}$ \\ SAmuel de Souza Neto***
}

\section{RESUMO}

Considerando o futebol palco de diferentes discussões, buscou-se averiguá-lo como profissão. A partir das teorias das profissões que se relacionam a uma origem artesã e a uma esfera social capitalista, procurou-se mapear o futebol e a relação dos jogadores e técnicos sob o enfoque da profissionalização relacionada à Educação Física. A pesquisa é de caráter exploratório, na qual se utilizou questionário e análise interpretativa como instrumentos. Os participantes acreditam na necessidade de uma formação teórica específica sem esquecer a prática, criando uma assimetria entre discurso e concepção de ação. Concluiu-se que para a Educação Física a questão de ser uma profissão fica mais evidente por ter uma base de formação específica e não estar alicerçada apenas na escola de ofício.

PALAVRAS-CHAVES: profissão - futebol - prática - profissionalização

\section{INTRODUÇÃO}

Wo Brasil, além de ser uma modalidade esportiva praticada 1 socialmente, visando aos mais diferentes objetivos, o futebol também é uma "paixão", um "estilo de vida" e uma instituição social que cultiva mitos, crenças, transforma seu percurso em uma empresa, que vende muito bem produtos como o "jogador de futebol", e se constitui grande fonte de renda. Para sustentar toda esta rede de formação e comércio encontram-se os clubes e os formadores, denominados

* Mestranda e licenciada em Educação Física pela UNESP.

** Mestrando e bacharel em Educação Física pela UNESP.

*** Doutor em Educação pela USP, licenciado em Educação Física, docente do Departamento de Educação do Instituto de Biociências da UNESP, professor do curso de Licenciatura em Educação Física e do Programa de Pós-graduação em Ciências da Motricidade. 
"técnico", "treinador" ou "professor" advindos da "escola de ofício" (exjogadores) e/ou de cursos superiores de Educação Física ou Esportes.

Com a regulamentação profissional da Educação Física no Brasil, pela Lei 9696 (BRASIL, 1998), criou-se uma estrutura muito ampla em torno desta modalidade esportiva e muitas questões começaram a ser discutidas nos diferentes campos de sua intervenção por abarcarem o corporativismo institucionalizado, principalmente nos esportes.

Logo, a Educação Física, vista como uma profissão, oferece um rol de competências necessárias para o profissional que atua em seus variados campos de interesse. Neste contexto, as "escolas de ofício" perderam o seu caráter de espaço de preparação ocupacional privilegiado, abrindo-se uma reserva de mercado.

Considerando esta premissa, alguns questionamentos começaram a surgir, como: O que de fato efetiva uma profissão? Quais são as características de um profissional, membro de uma profissão? Por que os atletas são considerados profissionais e qual a legitimidade de seu serviço para a sociedade?

Instigados por essas questões, entre outras, decidimos realizar este estudo para tentar compreender a dinâmica que fundamenta a formação destes "profissionais". Dentro do amplo cenário que existe, optamos pelo futebol, pois esta modalidade apresenta, para a sociedade brasileira, significados cada vez mais complexos devido às particularidades dos grupos que estão envolvidos neste meio, bem como diferentes possibilidades de estudo (GAMA, 1990). Além disso, o futebol foi o primeiro esporte a buscar a dita profissionalização, seja ela dos jogadores, do setor administrativo, dos treinadores, chegando às décadas de 19801990 como esporte "profissional", conquistando um status diferenciado no final do século XX e transformando-se em um fenômeno de importância socioeconômica, política, mercadológica e cultural.

No caso específico dos jogadores, através do Estado, tentou-se vincular sua profissionalização na década de 1930. Para Lawson (1984) e Hoffman e Harris (2002), apesar de os jogadores se denominarem profissionais, eles não podem ser assim considerados e o uso da palavra profissão ou profissional é dita de maneira inadequada, fugindo da sua definição. Para os autores, os jogadores exercem uma ocupação. De acordo com Lawson ${ }^{1}$ (1984), uma profissão é um tipo de ocupação, mas nem toda ocupação é uma profissão. 
Para muitas pessoas, o uso do termo profissional para o jogador de futebol referenda alguém que recebe alguma contribuição para determinada prática, diferenciando-o dos praticantes não remunerados (amadores). No entanto, isto também não condiz com o caso do atleta de futebol, pois hoje em dia, mesmo os amadores têm recebido contribuições para jogar. Já no caso de treinadores, eles estão envolvidos com uma profissão legitimada que é a Educação Física e/ou Esporte, sendo assim necessários alguns procedimentos e condutas para exercer esta função. Os treinadores são considerados profissionais diferentemente dos atletas por fazerem parte de uma profissão.

Entretanto, este processo de profissão ou não, dentro do futebol, não é claro para a sociedade e para os estudiosos da área. Assim, o objetivo deste trabalho foi realizar um estudo exploratório sobre a profissionalização do futebol, na perspectiva de averiguar o futebol como profissão, mapeando uma área de trabalho que se relaciona, também, com um campo de intervenção da Educação Física.

\section{PROFISSÃO: TEORIAS DE ESTRUTURAÇÃO ENQUANTO DINÂMICAS SOCIAIS}

A definição do que se entende por profissão não é muito fácil de se delimitar, pois existem compreensões que se distinguem enquanto enfoque e concepção de sociedade, bem como para a Educação Física.

Lawson (1984) assinala que a "profissão" é um tipo de ocupação de elite, em contraste com outros trabalhadores, pois seus membros ganham status e recompensas mais elevadas e acreditam que o seu trabalho é mais significativo, desfrutando de um maior controle sobre o mesmo. Um profissional é um membro de uma profissão, está comprometido com uma carreira, presta serviço à sociedade, pesquisa e orienta o seu campo de trabalho. De modo que ser um profissional significa deter os padrões específicos de sua profissão, mostrando a importância e necessidade de seus serviços.

Por sua vez, Contreras (2002) acredita que a característica de uma profissão é o saber profissional, a disposição em acatar decisões e o prestígio social. O que para Enguita (1991) seria competência, vocação, independência, licença e auto-regulação. 
Neste caminho, Hoyle, em estudo de Contreras (2002), coloca que uma profissão é uma ocupação que realiza uma função social crucial; requer destrezas específicas e são utilizadas em situações não totalmente rotineiras; embora o conhecimento da experiência seja importante deve ter um corpo de conhecimento sistemático que deve ser adquirido em formação no ensino superior para possibilitar a aquisição de valores, de um código de ética e que dará liberdade ao profissional. Também deve ter um alto grau de controle sobre o exercício das responsabilidades profissionais e um alto grau de autonomia em relação ao estado; além de responsabilidade e comprometimento, com um alto prestígio e nível de remuneração.

No entanto, há também a concepção em que vê na ocupação, em sua gênese, uma "escola de ofício", que aos poucos foi se articulando e constituindo-se no que é chamado de corporação. Em sua evolução algumas ocupações alcançaram o patamar de "profissão", recebendo uma maior apreciação e status social.

Sobre as ocupações, na obra de Rugiu (1998) ocorre a descrição do início da formação artesã e neste trabalho as "escolas de ofícios" configuram-se como espaços em que a tônica da formação, do aprendizado, se dá no fazer, tendo como referência o mestre e os segredos daquela "arte" que não são revelados a priori.

Se fizermos a transposição para o mundo dos afazeres técnicos, veremos esta continuidade no esporte. Durante um bom tempo se reproduziu algo cujo enfoque principal estava centrado na habilidade, sendo lapidada por alguém (que não deixa de ser o "mestre") na dimensão tradicional educativa, encontrada no "artesanato".

Em se tratando do esporte como profissão, Barros (1998) entende que o esporte de alto nível deve desempenhar uma função cultural importante na melhoria qualitativa das atividades esportivas em geral, se a preparação de profissionais for competente $\mathrm{e}$ atenderem as exigências desse esporte.

De fato quando se pensa na estrutura do futebol, principalmente no Brasil, se percebe que a busca pelo profissionalismo decorre do status que este irá proporcionar e a perspectiva de rentabilidade, aliada ao fato de se ter prazer em praticar o esporte futebol.

Para Sebreli (2005), a profissionalização dos jogadores de futebol não foi de modo algum uma exigência popular, mas sim um impulso 
do espírito do capitalismo, no qual o jogador buscou melhores salários e status social. Percebe-se que existe todo um percurso social por trás da profissão e suas configurações e que algumas vezes o uso da palavra não faz jus ao tipo de atividade exercida.

No caso da ligação entre a profissão Educação Física e o futebol a questão perpassa o entendimento de teoria e prática e a construção da solução dos problemas na prática profissional. Isto porque a área enfrenta desafios na divisão para formação de seus profissionais e in-

terpretações errôneas da prática e da teoria (BORGES, 2005).

A questão da teoria e da prática, assim como da sua relação, tendo como objetivo contextualizar o processo de profissionalização na sociedade teve como origem as idéias de um trabalho intelectual e trabalho manual, respectivamente. Os termos teoria e prática, derivados do grego, significam: a) Teoria: princípios básicos e elementares de uma arte ou ciência; sistema ou doutrina que trata desses princípios (CANDAU; LELIS, 1991). b) Prática, derivada de "práxis", tem o sentido de agir, podendo ser entendida como ato ou efeito de praticar; experiência nascida da repetição dos atos; costume (MICHAELIS, 2002).

Isto quer dizer que não se pode deixar de analisar, que neste caso, a teoria e a prática devem ser muito bem articuladas para se compreender as diferenças entre profissionais e "executadores". A prática, somente pela prática, fica alienada, bem como só a teoria, devendo ser ressignificadas e sistematizadas.

Estas são algumas das idéias decorrentes de um processo de profissionalização, aliadas às teorias das profissões e ao futebol. Porém, perguntamos: Qual é a relação contextual do futebol em seu processo de profissionalização e como ocorre seu delineamento?

\section{A PRÁTICA DO FUTEBOL: CAMINHOS DA PROFISSIONALIZAÇÃO}

O futebol, tal como conhecemos nos nossos dias, surgiu na Inglaterra no início do século XIX e a sua profissionalização por volta de 1880, quando as remunerações dos jogadores começaram a ocorrer para que estes pudessem se dedicar maior tempo aos treinamentos. No entanto, a Football Association (órgão legislador da época nesse país) se opunha a esta prática, ocasionando inúmeras desavenças entre 
as partes envolvidas. Contudo, após algum tempo, a profissionalização dos atletas foi aceita com algumas restrições pelos dirigentes, que continuariam com ações amadoras (HOBSBAWM; RANGER, 1984 e PRONI, 2000).

Neste contexto de semi-profissionalização ocorreu a primeira Copa do Mundo em 1930, sendo um marco do fim do amadorismo na Europa (DUARTE, 1998). Na tentativa de manter os principais jogadores, os países da América do Sul também começaram a se profissionalizar, pois os clubes europeus estavam contratando atletas dos países em que a prática não era profissionalizada (PRONI, 2000).

No caso do Brasil, a profissionalização do futebol começou o seu processo efetivo em 1931, com a inclusão do futebol no rol das profissões que deveriam ser regulamentadas na Legislação Social e Trabalhista e teve a participação do Estado nos principais momentos de sua reestruturação profissional (CALDAS, 1994).

No entanto, para Proni (2000), o marco da profissionalização foi em 1933 com a criação da Federação Brasileira de Futebol (FBF), ganhando status em 1937, quando a Confederação Brasileira de Desporto (CBD) reconheceu este processo de profissionalização. É interessante também relatar que este processo de profissionalização do futebol só foi possível porque existia, e continua existindo, um público disposto a pagar para assistir ao espetáculo (BETTI, 1997).

Na década de 1940, o estatuto de profissionalismo já havia sido implantado em vários estados, no entanto, somente em 1967 é instituída, explicitamente, a lei do passe, dando ao jogador um grande passo para o profissionalismo, com a Deliberação 09/67, a qual se estipula a transição de um jogador para outra equipe e dispõe sobre sua participação no passe. Em 1976, houve outro avanço, seguindo a trilha do profissionalismo, com a Lei 6.354 que dispôs sobre as relações de trabalho do atleta profissional de futebol e dos técnicos. Esta lei caracterizava as funções do empregador (Associação Desportiva) e do empregado, explicitando quais as obrigações e deveres das partes envolvidas e garantiram algumas conquistas trabalhistas já adquiridas por outras categorias profissionais, mesmo o jogador ainda sendo encarado como "patrimônio" do clube, podendo ser vendido ou emprestado (CARDOSO, 1991).

Adentrando na temática de quem trabalha no futebol, não sendo jogador, temos o profissional de Educação Física, com seu marco pro- 
fissional, no futebol, na Copa de 58, na qual havia profissionais exclusivos para a preparação física e a recuperação dos atletas. Nesta época se cobrava uma mudança dos métodos extracampo e isto se corroborou na Copa de 70, quando ocorre toda uma planificação do treinamento com profissionais especialistas.

A presença de um profissional qualificado para trabalhar como treinador foi instaurado em 1941 pelo Decreto-Lei 3.199, que reconheceu como técnico o indivíduo formado pela Escola de Educação Física e Desporto da Universidade do Rio de Janeiro, afinal antes desta data, os técnicos advinham em um contínuo, ou seja, passavam de jogadores a técnicos, sem nenhuma formação específica (LEAL, 2001). Já a lei de 1976, artigo 27, garante ao ex-jogador a possibilidade de trabalhar como técnico, preparador físico ou auxiliar, referenciando-o como monitor de futebol (CARDOSO, 1991).

Se pensarmos a questão da prática, notaremos que está bem alicerçada e permite que todo um contexto de reprodução seja "passado adiante": técnicos que eram ex-jogadores, técnicos improvisados e a Educação Física buscando um espaço social. Contudo, a ocupação de treinador profissional de futebol só foi regulamentada em 1993, por incentivo da Associação Brasileira de Treinadores de Futebol, pela Lei 8650, que deu pleno exercício profissional aos diplomados em Educação Física e aos profissionais que já exerciam esta função antes desta por, no mínimo, seis meses. Além disso, a lei estabeleceu que se aplicassem aos treinadores as mesmas legislações do trabalho e da previdência social.

No entanto, mesmo com a profissionalização, o treinador ainda é chamado de técnico. Mas entre os jogadores, o termo "professor" é cada vez mais incorporado, indicando certa ascensão da categoria (SANTOS, 2002).

A partir destas nuances, podemos ter uma compreensão distinta da dita "profissionalização" para os atletas e treinadores de futebol. No caso do exercício profissional, do profissional de Educação Física que atua como treinador, preparador físico, auxiliar técnico, etc., o contexto do futebol apresenta-se como uma profissão que foi regulamentada em $1^{\circ}$ de setembro de 1998, com a proposta de um corpo de conhecimentos que são aplicados. Mesmo tendo algumas características da "profissão de jogador de futebol”, o profissional de Educação Física consegue alavancar dentro da sociedade um status de representação da sua profissão. 
Esta questão de ser um profissional ou não é uma longa discussão, percebendo-se que existe todo um esforço em dar legitimidade a este campo de atuação, dando status e reconhecimento social aos seus pares, como por exemplo, a Lei Pelé, no quesito do passe do jogador, no estatuto do torcedor, entre outras, que não deixam de ser medidas significativas para a conquista de um espaço em meio a tantas profissões emergentes ou, até mesmo, já estruturadas.

Portanto, dentro deste contexto o que se procura é fazer um mapeamento dessa realidade, considerando o que a produção especializada diz e o que os participantes deste campo de atuação discorreram a respeito.

\section{O FUTEBOL ENTRA EM CAMPO: NUANCES DA PRÁTICA PROFISSIONAL}

Instigados por estas questões e nuances, realizamos um estudo exploratório, preliminar, de análise qualitativa, com profissionais que trabalham com o futebol. Escolhemos o questionário, pois é considerada uma técnica que busca identificar, comparar e confirmar as respostas dos participantes/sujeitos investigados. Ele contém uma lista de perguntas, cuja temática corresponde, em princípio, a uma tradução das questões da pesquisa. O questionário foi aplicado em quatro profissionais que atuam no futebol.

\section{O Estudo}

A primeira parte do questionário (Quadro 1) visava saber quanto tempo o profissional trabalha com o futebol e qual é o cargo exercido.

\begin{tabular}{|c|c|c|}
\hline Profissionais & Tempo de atuação & Função \\
\hline A & 1,5 anos & Professor (técnico) \\
\hline B & 5 anos & Professor de futebol \\
\hline C & 9 anos & Professor de futebol \\
\hline D & 17 anos & Técnico assistente \\
\hline
\end{tabular}

Quadro 1 - Tempo e função profissional

É possível notar que dois profissionais estão em fase de iniciante com aquisição de experiências e os outros dois já estão estabilizados. 
Com relação à prática esportiva, para se compreender quais foram as influências que encaminharam estes profissionais para o futebol, houve quatro perguntas:

1) Durante a sua infância e adolescência, quais foram as experiências esportivas que você considera mais significativas?

2) Como ocorreu a sua inserção no futebol?

3) Na prática desse esporte, antes de chegar ao cargo ocupado hoje, quais foram as funções ou papéis que você exerceu?

4) Neste percurso, considerando o passado e o presente, você participou ou freqüentou algum tipo de curso (futebol) relacionado à federação, associação, entre outros? Se sim, quais?

Dois profissionais responderam estas perguntas, mas pode ser verificado, no Quadro 2, que o futebol integra as experiências de infância, o que denominamos de socialização primária e ambos praticaram e acabaram se encaminhando como um processo natural, visto na escola de ofício.

\begin{tabular}{|c|c|c|c|c|}
\hline Profissionais & $\begin{array}{c}\text { Experiências } \\
\text { significativas } \\
\text { na infância }\end{array}$ & $\begin{array}{c}\text { Inserção no } \\
\text { futebol }\end{array}$ & $\begin{array}{c}\text { Funções que } \\
\text { exerceu antes } \\
\text { da atual }\end{array}$ & $\begin{array}{c}\text { Participação } \\
\text { em curso da } \\
\text { Federação }\end{array}$ \\
\hline A & Futebol & $\begin{array}{c}\text { Jogando na } \\
\text { rua }\end{array}$ & $\begin{array}{l}\text { Foi praticante } \\
\text { e uniu teoria e } \\
\text { prática }\end{array}$ & Não \\
\hline B & $\begin{array}{c}\text { Futebol } \\
\text { basquete }\end{array}$ & $\begin{array}{c}\text { Participar de } \\
\text { uma equipe }\end{array}$ & $\begin{array}{l}\text { Estagiário du- } \\
\text { rante 2 anos } \\
\text { para exercer o } \\
\text { cargo }\end{array}$ & Não \\
\hline
\end{tabular}

Quadro 2 - Socialização primária

Sobre a formação de cada participante foram elencadas perguntas sobre a realização de uma graduação em Educação Física ou em outra área e a realização de algum curso de pós-graduação ou especialização.

\begin{tabular}{|c|c|c|c|}
\hline Profissionais & $\begin{array}{c}\text { Graduação em } \\
\text { Educação Física }\end{array}$ & Outra graduação & Pós-graduação \\
\hline A & Sim & Não & Não \\
\hline B & Sim & Não & Sim \\
\hline C & Sim & Não & Não \\
\hline D & Não & Não & Não \\
\hline
\end{tabular}

Quadro 3 - Formação em Educação Física 
Três dos quatros participantes (Quadro 3) realizaram um curso de graduação na área de Educação Física, sendo que um também realizou uma especialização. Embora carreguem traços da escola de oficio, também levam em consideração os encaminhamentos apontados por Hoyle (apud CONTRERAS, 2002) quando aponta que para ser profissional é necessário ter permanecido um tempo no ensino superior.

$\mathrm{Na}$ seqüência, serão apresentadas as questões relacionadas ao profissional de Educação Física e sua relação com o futebol. Neste sentido, foi feita uma pergunta relacionada ao Conselho Regional de Educação Física e a adesão destes profissionais. A resposta apresentou parcialidade, pois dois participantes são registrados (B e C) e dois não são registrados (A e D).

Em outra questão sobre o conhecimento mais importante para se trabalhar com o futebol as respostas permaneceram relacionadas à prática, teoria ou outros saberes.

\begin{tabular}{|l|l|}
\hline Profissionais & \multicolumn{1}{c|}{ Conhecimentos importantes } \\
\hline A & $\begin{array}{l}\text { Unir a teoria com a prática, sabendo modelar as atividades e as } \\
\text { cobranças para as diferentes faixas etárias. }\end{array}$ \\
\hline B & É necessário saber diversos tipos de treinamento. \\
\hline C & $\begin{array}{l}\text { Estabelecer um objetivo e procurar alcançá-lo da forma mais prática } \\
\text { e com muita eficácia. }\end{array}$ \\
\hline D & $\begin{array}{l}\text { A pergunta é muita aberta. Posso responder, por exemplo, que é } \\
\text { a tática, mas para isso tem que ter o treinamento, tem que ter o } \\
\text { diálogo, para trabalhar com o futebol temos que ter um conjunto } \\
\text { de sabedorias. }\end{array}$ \\
\hline
\end{tabular}

Quadro 4- Conhecimentos práticos e teóricos

No Quadro 4 fica visível a necessidade de se ter a teoria e a prática em união, ou seja, como foi proposto por Candau e Lelis (1991), elas devem caminhar juntas em associação e não em preponderância de uma sobre a outra. Também existe o discurso do alcance de metas e o diálogo que adentram na esfera de um saber organizacional da própria prática e da experiência.

A pergunta subseqüente foi sobre a necessidade de ser formado em Educação Física para trabalhar com futebol nas funções de: treinador, preparador físico, auxiliar técnico e preparador de goleiros. Todos os participantes responderam que sim e apresentaram (Quadro 5) as seguintes justificativas. 


\begin{tabular}{|c|l|}
\hline Profissionais & \multicolumn{1}{c|}{ Justificativa } \\
\hline A & $\begin{array}{l}\text { Não adianta você só saber a prática, se não há um embasamento } \\
\text { teórico, pois é através da teoria que você acha solução para } \\
\text { problemas que surgem na prática. }\end{array}$ \\
\hline B & $\begin{array}{l}\text { É necessário que o técnico profissional tenha formação na área, } \\
\text { para trabalhar baseado em conhecimento científico, apoiado em } \\
\text { estudos e técnicas testadas e aprovadas. }\end{array}$ \\
\hline C & $\begin{array}{l}\text { Porque os treinadores precisam ter conhecimentos mais } \\
\text { aprofundados sobre: desenvolvimento motor, fisiologia, } \\
\text { pedagogia, etc. }\end{array}$ \\
\hline D & $\begin{array}{l}\text { Porque um preparador físico, por exemplo, vai saber dosar o } \\
\text { tempo de alongamento e aquecimento para uma partida. Cada } \\
\text { um tem a sua importância, nesse caso falei do preparador físico. }\end{array}$ \\
\hline
\end{tabular}

Quadro 5 - Justificativas sobre a formação

Esta questão se mostrou extremamente interessante, pois se voltarmos ao histórico sobre como foi a formação do técnico que trabalhava com o futebol, descrito no início, perceberemos que existe um avanço no sentido de se ter uma preparação específica para exercer esta função e não simplesmente passar de jogador a técnico.

Foi elaborada uma questão sobre a importância do saber fazer para quem trabalha com o futebol. Todos os participantes reconheceram que este saber é fundamental e a justificativa foi apontada no âmbito da demonstração, ficando notório que o gesto técnico fundamenta, na opinião destes participantes, a credibilidade do profissional (Quadro 6).

\begin{tabular}{|c|l|}
\hline Profissionais & \multicolumn{1}{c|}{ Justificativa } \\
\hline A & $\begin{array}{l}\text { O "saber fazer" é importante, pois muitas vezes é mais fácil } \\
\text { explicar um exercício demonstrando, porém o "saber fazer" não é } \\
\text { o suficiente para "saber ensinar". }\end{array}$ \\
\hline B & $\begin{array}{l}\text { Pois como executar treinamentos se não tem conhecimento sobre } \\
\text { o "saber fazer". }\end{array}$ \\
\hline C & $\begin{array}{l}\text { Na minha opinião, o "saber fazer" tem que estar acompanhado de } \\
\text { estudo e aprimoramento. }\end{array}$ \\
\hline D & $\begin{array}{l}\text { Sim, porque as pessoas com quem vamos trabalhar perceber que } \\
\text { o treinador sabe o que está pedindo ficam com confiança nessa } \\
\text { pessoa. E a confiança mútua é muito importante. }\end{array}$ \\
\hline
\end{tabular}

Quadro 6 - Justificativas sobre o saber fazer 
À pergunta sobre a participação do ex-atleta nas funções de treinador, preparador físico, auxiliar técnico e preparador de goleiros, todos foram unânimes em assinalar a alternativa que dizia: Importante, mas é necessário que o ex-atleta tenha formação em Educação Física, reafirmando a questão profissional que tem uma formação e ocupa um lugar de status social, prestando um serviço para a sociedade. As justificativas foram baseadas na aquisição de conhecimentos científicos, sendo necessário estudar para se qualificar e também chamaram atenção sobre a importância das experiências destes atletas que podem contribuir para o futebol.

(4) importantíssimo (3) importante (2) pouco importante (1) sem nenhuma importância

\begin{tabular}{|c|c|c|c|c|}
\hline COMPETÊNCIAS & 4 & 3 & 2 & 1 \\
\hline $\begin{array}{l}\text { Planejar treinos, utilizando métodos de } \\
\text { treinamento e escalas de periodização em função } \\
\text { do calendário. }\end{array}$ & ABCD & & & \\
\hline Ser amigo dos atletas e dos dirigentes. & AD & BC & & \\
\hline $\begin{array}{l}\text { Ter conhecimentos nutricionais, fisiológicos, } \\
\text { psicológicos, biomecânicos e de primeiros } \\
\text { socorros. }\end{array}$ & A & BC & $\mathbf{D}$ & \\
\hline $\begin{array}{l}\text { Ser honesto mediante contrato e na relação com } \\
\text { os atletas. }\end{array}$ & ABCD & & & \\
\hline Ser ético e respeitar o adversário. & ABCD & & & \\
\hline $\begin{array}{l}\text { Saber aplicar e utilizar testes psicológicos, } \\
\text { físicos, técnicos, táticos e fisiológicos. }\end{array}$ & $\mathbf{C}$ & AB & $\mathbf{D}$ & \\
\hline $\begin{array}{l}\text { Ter conhecimentos "práticos" e malandragem } \\
\text { ("jogo de cintura"). }\end{array}$ & $\mathbf{D}$ & B & AC & \\
\hline Ter conhecimentos das táticas e das técnicas. & ABCD & & & \\
\hline $\begin{array}{l}\text { Ter realizado curso de graduação e/ou pós- } \\
\text { graduação. }\end{array}$ & ABCD & & & \\
\hline Ter disciplina, responsabilidade e objetividade. & ACD & B & & \\
\hline Ter liderança. & ABD & & & \\
\hline $\begin{array}{l}\text { Saber tomar decisões, comunicar-se bem e } \\
\text { manter-se informado. }\end{array}$ & ABD & & & \\
\hline $\begin{array}{l}\text { Ter conhecimento histórico - cultural da } \\
\text { modalidade e entender de políticas públicas (leis } \\
\text { desportivas). }\end{array}$ & & ABC & D & \\
\hline
\end{tabular}

Quadro 7 - Importância das competências 
As duas questões seguintes referem-se ao conhecimento do código de ética da Associação Brasileira de Treinadores de Futebol e sobre a lei para o exercício profissional dos treinadores de futebol. Nenhum dos participantes tem conhecimento a respeito.

Aúltima questão diz respeito às competências que os profissionais consideram importantíssimas, importantes, pouco importante ou sem nenhuma importância para se trabalhar com futebol.

Como pode ser observado no Quadro 7, os participantes foram unânimes em apontar o planejamento, ser ético e honesto, bem como ter realizado graduação e ter conhecimentos técnicos e táticos como importantíssimo. Já disciplina, liderança e tomada de decisões foram vistos como importantíssimo, mas houve uma abstinência. Sobre conhecimentos nutricionais, fisiológicos, psicológicos, biomecânicos e de primeiros-socorros, utilização de testes, ser amigo do dirigente e ter conhecimento histórico-cultural da modalidade teve maior incidência o quesito importante. E ter jogo de cintura foi considerado, na maior parte das respostas, como pouco importante.

\section{O FUTEBOL... ONDE ESTÁ A PROFISSÃO?}

No decorrer deste processo, de compreender como o futebol foi se constituindo relacionado a sua profissionalização (jogadores, técnicos, clubes etc.), é importante notar que o futebol segue uma linha tênue entre a influência da escola de ofício, ou seja, a sua reprodução enquanto algo extremamente prático e a sua concepção mais acadêmica, como a sua posição dentro de uma área de conhecimento, o qual de certa forma pode ser concebido como um dos seus campos de atuação, ou como um objeto de estudo.

Esta noção fica evidente ao se observar as respostas dos participantes quando se referem à importância do saber-fazer, bem como à origem da iniciativa profissional, advinda de uma experiência anterior.

Percebemos que o futebol vem lutando para se estruturar como profissão, no sentido de ter status, reconhecimento social. Todavia, se perde o rumo quando se entra no enfoque da produção de um determinado conhecimento, expondo como resultado a performance, o espetáculo, que, de certa forma, acalentam alguns itens, mas superficialmente, sem entrar na demanda das necessidades sociais. 
Para os profissionais de Educação Física, inseridos neste contexto, esta menção de profissão fica um pouco mais evidente, pois eles estão envolvidos por sua área de formação, apesar de utilizarem muito da experiência prática, como foi anteriormente discutido. Desta forma, para eles, o futebol adquire um caráter mais próximo de uma profissão, pois produzem conhecimentos para a sua área e demonstram sua importância neste contexto. E ainda que não consigam seguir dentro do futebol, conseguem voltar para sua área de formação, continuando a exercer a profissão de Educador Físico.

Neste compasso existem algumas lacunas e o "fio da meada", aquilo que daria suporte ao futebol, ainda é muito frágil, pois como se podem notar, nos quadros dos resultados, os profissionais acreditam na constituição de saberes importantes, como o embasamento teórico, uma formação específica. No entanto, o caráter prático se distancia deste pensamento, causando um desnível entre o discurso e a concepção de ação.

Os encaminhamentos finais, pertinentes ao enfoque deste trabalho, discorrem sobre a direção de que se pode considerar que o futebol, enquanto uma profissão, vem avançando em sua constituição e existe certa dependência de áreas influentes como as Ciências do Esporte e a própria Educação Física, para o seu crescimento e delineamento como tal.

Dessa forma, com as urgências sociais e as cobranças por qualificações e certificações, tanto atletas como técnicos e profissionais de outras áreas que adentram no "mundo do futebol" têm direcionado uma maior atenção para o comprometimento e responsabilidade de seu trabalho, garantindo uma profissionalidade, um compromisso social, moral e que se encaminha para a autonomia.

No mapeamento apresentado permitimos aguçar a visão para uma nova perspectiva dentro da Educação Física e do próprio futebol, demonstrando certas etapas e níveis para a estruturação do que foi definido e intitulado como "profissão".

\section{Football: questions and reflections on this "occupation"}

\section{ABSTRACT}

Taking football as the stage for different discussions, we have tried to assess it as an occupation. Starting from the theories of occupations that relate both to an artisan origin and to a capitalist social sphere, we have attempted to map football and its relation to 
players and coaches by means of linking their professionalization to the professional field of Physical Education. This research work is of the exploratory type, and questionnaires and interpretative analysis were used as instruments. The participants believe it is necessary to have a specific theoretical education that does not dismiss practice, which creates an assimetry between speech and action. Results show that occupation is a more evident concept among Physical Education professionals since they have a specific educational basis which is not founded merely in practice.

KEYWORDS: profession - football - practice - professionalization

\section{El fútbol: preguntas y reflexiones sobre esta "profesión”}

\section{RESUMEN}

Considerando al fútbol como el objeto de diversas discusiones, se intentó averiguarlo como profesión. A partir de las teorías de las profesiones que se relacionan a un origen artesano y una esfera social del capitalista, se intentó analizar el fútbol y la relación de los jugadores y técnicos bajo el enfoque de la profesionalización relacionada a la Educación Física. La investigación tiene carácter exploratorio, donde se utilizó un cuestionario y análisis interpretativo como instrumentos. Los participantes creen que la necesidad de una formación teórica específica sin olvidarse de la práctica, creando una asimetría en los términos del discurso y de la concepción de acción. Se concluye que para la Educación Física la profesión es más evidente por tener una base de formación específica y no se centra solamente en escuela del oficio.

PALABRAS-CLAVE: profesión - fútbol - práctica - profesionalización

\section{NOTA}

1 Tradução Atílio De Nardi Alegre.

\section{REFERÊNCIAS}

BARROS, J. M. C. Cidadania e a prática esportiva formal e não formal. Revista Brasileira de Ciência do Esporte, Florianópolis, v.19, n. 3, p. 99-105, 1998.

BETTI, M. Violência em Campo: dinheiro, mídia e transgressão às regras no futebol espetáculo. Ijuí: Unijuí, 1997.

BORGES, C.A formação dos docentes de Educação Física e seus saberes profissionais. In: BORGES, C.; DESBIENS, J-F. (Orgs.). Saber, formar e intervir para uma educação física de mudança. São Paulo: Autores Associados, 2005. p. 157-190. 
BRASIL. Congresso Nacional. Lei n. 9696, de $1^{\text {o }}$ de setembro de 1998.

CALDAS, W. Aspectos sócios políticos do futebol brasileiro. Revista USP, São Paulo, n. 22, p. 40-49, jun./jul./ago. 1994.

CANDAU, V. M.; LELIS, I. A. A relação teoria-prática na formação do educador. In:

Vozes, 1991. p. 49-63.

CARDOSO, E. R. Competências básicas necessárias ao jogador de meio-campo atuante em equipes de futebol na categoria profissional: uma aplicação da técnica Delfos. 1991. 168 f. Dissertação [Mestrado em Educação Física] - Faculdade de Educação Física, Universidade Gama Filho, Rio de Janeiro, 1991.

CONTRERAS, J. A autonomia de professores. São Paulo: Cortez, 2002.

DUARTE, O. Enciclopédia - todas as Copas do Mundo. São Paulo: Makron Books, 1998.

ENGUITA, M. F. A ambigüidade da docência: entre o profissionalismo e a proletarização. Teoria e Educação, Porto Alegre, v. 4, n. 4, p. 41-61, 1991.

GAMA, W. Características sociais do jogador de futebol profissional na $1^{a}$ divisão do estado de São Paulo. 1990. 70 f. Dissertação [Mestrado em Educação Física] - Escola de Educação Física, Universidade de São Paulo, São Paulo, 1990.

HOBSBAWM, E.; RANGER, T. As invenções das tradições. Rio de Janeiro: Paz e Terra, 1984.

HOFFMAN, S. J.; HARRIS, J. C. Cinesiologia: o estudo da atividade física. Porto Alegre: Artmed, 2002.

LAWSON. H. Invitation to physical education. Champaign: Human Kinectics Book, 1984.

LEAL, J. C. Futebol: arte e oficio. 2 ed. Rio de Janeiro: Sprint, 2001.

MICHAELIS. Dicionário Michaelis-UOL. São Paulo: Melhoramentos, 2002. 1 CD-ROM. 
PRONI, M. W. A metamorfose do futebol. Campinas, SP: Unicamp, 2000.

RUGIU, A. S. A nostalgia do mestre artesão. Campinas: Autores Associados, 1998.

SANTOS, L. M. V. V. A evolução da gestão no futebol brasileiro. 2002. 105 f. Dissertação [Mestrado em Administração] - Escola de Administração de Empresas, Fundação Getúlio Vargas, São Paulo, 2002.

SEBRELI, J. J. La era del fútbol. Buenos Aires: Debolsillo, 2005.

Recebido: 26 de setembro de 2006 Aprovado: 17 de novembro de 2006

Endereço para correspondência: Fabio Barbieri Rua 8b, 1171 - Vila Indaiá Rio Claro - São Paulo CEP 13506-739

E-mail: barbieri@rc.unesp.br 
